\title{
EL CONTROL DE ESCRIBANOS PÚBLICOS EN LA CORONA CASTELLANA: UN JUICIO DE RESIDENCIA EN LA TIERRA DE SEVILLA (1570)
}

\section{Monitoring public scribes at the castillian Crown: a juicio de residencia at Sevilla's hinterland (1570)}

\section{Ma Luisa DOMÍNGUEZ-GUERRERO}

Universidad de Sevilla

marialuisadominguez@us.es

Fecha de recepción: 15/05/2018

Fecha de aceptación: 14/01/2019

RESUMEN: En Castilla, desde la Edad Media, la labor de los oficiales públicos fue periódicamente auditada con el fin de garantizar el correcto cumplimiento de sus obligaciones y la observancia de la legislación, para lo que la Corona empleó distintos instrumentos de control que fueron evolucionando y perfeccionándose a lo largo del tiempo. En este trabajo se analiza uno de estos mecanismos, el de los juicios de residencia, aplicándolo al caso de los escribanos públicos que trabajaban en término jurisdiccional del concejo de Sevilla durante la segunda mitad del siglo XVI. A través de la documentación oficial generada por el juez de residencia, se determinará cuál era el nivel de cumplimiento que estos oficiales públicos, por cuyas manos pasaban los trámites económicos y administrativos de sus villas, hicieron de la normativa vigente

Palabras clave: juicio de residencia; escribanos; penas; documentos.

ABSTRACT: Since the middle Ages, in Castille, the work performed by public officers was regularly supervised in order to guarantee that they 
were fulfilling their obligation faithfully and according to the law. For this, the Crown employed different instruments, which evolved along the years. This paper analyses one of these instruments, the juicio de residencia, focusing on the public scribes working on the sevillian hinterland during the second half of the XVIth Century. Through the official documentation generated by the residencia judge, we will determine how these public officers applied the current legislation.

Keywords: Public scribes; Legislation; Sentences; Jugdes.

\section{LA RESIDENCIA A LOS ESCRIBANOS}

El correcto cumplimiento de la normativa relativa al desempeño de los oficios públicos supuso, ya desde la Edad Media, un asunto de vital importancia para la Corona castellana, siempre interesada en garantizar el adecuado funcionamiento de las distintas instituciones del Reino (Collantes de Terán, 1998: 153). Por esta razón, la labor de los oficiales públicos fue periódicamente auditada a través de diferentes mecanismos de control orquestados por la Corona que fueron evolucionando y perfeccionándose a lo largo del tiempo, como fueron las visitas, las pesquisas y los juicios de residencia.

Aunque tradicionalmente estos tres conceptos han sido con frecuencia empleados de forma sinónima, lo cierto es que responden a tres realidades muy cercanas entre sí pero que difieren en algunos aspectos (Zumalacárregui, 1946: 917-921). Por ejemplo, la visita era una investigación que se realizaba de forma esporádica y sin que existiera una cronología precisa sobre instituciones o conjuntos de oficiales que seguirían ocupando sus cargos mientras la visita era llevada a cabo. Frente a ello, la pesquisa es una averiguación sobre una persona o personas concretas sobre un asunto determinado, siendo obligación del pesquisidor remitir sus resultados a una autoridad judicial superior (García, 1996: 120). Y finalmente, el juicio de residencia era una auditoría formal y completa, dirigida por un juez, que se realizaba sobre el total de las actividades desarrolladas por un cargo público durante el tiempo que desempeñó su labor, o de forma periódica en el caso de los oficios vitalicios (González, 1978: 193).

En este último apartado sería donde se encuadrarían las investigaciones realizadas sobre la labor y buen o mal hacer de los escribanos públicos, un oficio que, desde su establecimiento en el siglo XIII, fue entregado a sus ocupantes con carácter vitalicio y renunciable (Ostos, 2012: 520). Precisamente en esta corporación, la de los escribanos públicos de Castilla, y en los mecanismos de vigilancia y control que las instituciones de poder, dirigidas por la Corona, emplearon para garantizar el correcto y legítimo desempeño de este oficio se centra este trabajo. Las fuentes

Ediciones Universidad de Salamanca / అ@@ Stud. his., H. ${ }^{a}$ mod., 42, n. 1 (2020), pp. 223-253 
para esta investigación se hallan en el Archivo General de Simancas, dentro de los fondos de la Cámara Real de Castilla, donde localizamos un gran conjunto de libros cosidos conteniendo toda la documentación que se generó durante el juicio de residencia al que se sometieron todos los oficiales públicos de la ciudad de Sevilla y su término jurisdiccional en 1570. Con ellas se ha llevado a cabo este estudio que esperamos arroje nueva luz sobre el fenómeno de los juicios de residencia a los escribanos públicos.

Los procedimientos de supervisión y control de los oficiales públicos tienen su origen en el mundo romano, siendo el siglo XIII, con la legislación alfonsí, el momento en que reinstauran en la administración castellana, estableciéndose su necesidad para auditar la labor de jueces y otros oficiales públicos ${ }^{1}$. Ya en el siglo XIV, en las Cortes de Valladolid de 1312, el sistema se consolidará quedando establecido que la vigilancia de los oficiales sería llevada a cabo por otros cargos públicos que ya estarían previamente desempeñando su labor en cada lugar (González, 1978: 195 y 219).

La inestabilidad política que marcó el siglo XV castellano y la debilidad del poder real limitó la efectividad de estas prácticas, por lo que los Reyes Católicos determinaron volver a emitir una normativa que regulase y asentase de nuevo estas políticas, poniendo un especial énfasis en la vigilancia y control de las autoridades políticas y administrativas que representaban a la Corona y gobernaban en su nombre los distintos territorios, como los asistentes y corregidores (Collantes de Terán, 1998: 154). Si bien la primera aproximación a la materia se halla en las Cortes de Toledo de 1480 (Domínguez Ortega, 1999: 140), el verdadero impulso a los sistemas de control de los oficiales públicos no llegaría hasta los años finales de la centuria. En 1494, aprovechando que la ciudad de Murcia iba a cambiar de corregidor y que el nuevo ocupante del cargo se hallaba aún en la Corte, se elaboró para él un cuaderno conteniendo unas instrucciones precisas para realizar la residencia al corregidor saliente y sus oficiales, en lo que R. Serra Ruiz vio un claro experimento de la normativa que más adelante promulgarían para toda Castilla (Serra, 1968). Esta normativa vio la luz en el año 1500 mediante una Real Pragmática dada en Sevilla el 9 de junio, que recoge paso a paso el proceso que era necesario seguir para la realización de una pesquisa, visita o residencia (Collantes de Terán, 1998: 151).

Este sistema será el que siga vigente a lo largo de la Edad Moderna, que es el periodo en el que se encuadra este presente estudio. En un principio, estas auditorías serían realizadas sobre los oficiales salientes por los nuevos ocupantes del cargo, quienes analizarían el trabajo de sus predecesores y de las personas a su cargo. Sin embargo, tal y como el propio monarca explica en una real Provisión del año $1564^{2}$,

1. Espéculo de Leyes, (IV, 3, 2).

2. Archivo General de Simancas [en adelante AGI], Cámara Real de Castilla [en adelante CRC], 276.

Ediciones Universidad de Salamanca / అ@@ Stud. his., H. ${ }^{a}$ mod., 42, n. 1 (2020), pp. 223-253 


\section{Ma LUISA DOMÍNGUEZ-GUERRERO \\ EL CONTROL DE ESCRIBANOS PÚBLICOS EN LA CORONA CASTELLANA: \\ UN JUICIO DE RESIDENCIA EN LA TIERRA DE SEVILLA (1570)}

este sistema adolecía de varios fallos, entre ellos, que los nuevos ocupantes del gobierno municipal eran frecuentemente muy laxos en la aplicación de la normativa, bien por carecer de tiempo para llevarla a cabo diligentemente, bien por no enemistarse con las personas que a partir de ese momento estarían a su cargo, bien porque ellos mismos pensaban seguir cometiendo los mismos hechos delictivos ${ }^{3}$.

Por esta razón, Felipe II estableció que las residencias deberían de ser llevadas a cabo por jueces independientes y ajenos al gobierno del lugar que visitarían, además de ser personas de letras y con conocimientos profundos de derecho (Usunáriz, 1998: 494). Éstos acompañarían al corregidor entrante en su llegada a su nuevo destino y durante un periodo de hasta noventa días se dedicarían a auditar las actuaciones administrativas y económicas desempañadas por los cargos salientes, así como a examinar las actuaciones de otros oficiales públicos ejerciendo su labor en el territorio, entre los que se hallaban los escribanos públicos ${ }^{4}$.

Uno de estos jueces fue al que se comisionó para realizar una visita de residencia en el territorio de Sevilla entre mayo y julio de 1570, coincidiendo con la renovación en el cargo de asistente de la ciudad ${ }^{5}$. Antes de la partida del oficial saliente, Francisco Hurtado de Mendoza, conde de Monteagudo, se envió a la ciudad al licenciado Morales con una provisión ordenándole hacer una pesquisa y residencia de su actuación y la de los oficiales bajo su cargo, poniendo especial énfasis en el cumplimiento de las Leyes de Toledo (1480) y en la comisión de pecados públicos ${ }^{6}$.

Esta Real Provisión, expedida en Sevilla a 10 de mayo de 1570, fue recibida por los oficiales del concejo hispalense a 13 del mismo mes, cuando fue leída en una reunión extraordinaria de los capitulares. Tomé Sánchez, escribano del cabildo, dejó

3. AGI, CRC, 276: «Por tener gratos para sus residencias a los corregidores y otras personas que han de dar qüenta de los propios de los conçejos non las toman con la diligençias y cuydados que conviene y dissimulan con los dichos regidores en los exçesos que han hecho y por la misma causa dexan de castigar a los scriuanos del número, disimulando con ellos sus delictos y excessos y dexan de remediar muchos abusos que los corregidores e juezes pasados han yntroduçido contra leyes e pregmáticas destos reynos y contra el bien público dellos por ser ellos mismos interesados en ellos»

4. AGS. CRC. 276.

5. Una situación similar vivió la Alpujarra granadina apenas una década antes, cuando fue realizada la visita del licenciado Huarte (Osorio Pérez y De la Obra, 2014).

6. AGS. CRC. 276: «[...] Os mando que vays a la dicha çiudad de Seuilla y toméys residencia al dicho don Francisco Hurtado de Mendoza, conde de Monteagudo, y a sus alcaldes y alguaziles mayores y teniente y otros offiçiales que allí tiene por término de cien días.[...] Os informad de offiçio cómo y de qué manera el dicho don Françisco Hurtado de Mendoza y sus officiales han usado sus offiçios y executado la nuestra justiçia, speçialmente en los pecados públicos y cómo se han guardado las leyes fechas en las Cortes de Toledo. [...] Y otrosy tomad residençia a los veintyquatros, fieles executores, jurados y scriuanos y procuradores que ay en la dicha çiudad y si residen sus offiçios y cómo vsan dellos; y si alguno tiene quexa dellos, que lo venga a demandar ante vos y hazed justiçia a los querellosos [...]»

Ediciones Universidad de Salamanca / అ@@ Stud. his., H. ${ }^{a}$ mod., 42, n. 1 (2020), pp. 223-253 
constancia de su lectura y de la declaración de obediencia del nuevo Asistente ${ }^{7}$. Una vez aceptada la realización de una visita el siguiente paso era su organización. El licenciado Morales, comisionado para la residencia, se encargaría naturalmente de realizar la visita en la ciudad, mientras que para desplazarse a los pueblos y villas del territorio se seguirían los ya citados Capítulos de Residencia dados por los Reyes Católicos, que ordenaban que se comisionase a cierto personal de confianza para que fuesen de villa en villa reuniendo las pruebas que el juez de residencia requería para dar su veredicto (Collantes de Terán, 1998: 168). Estos enviados serían, por una parte, alguaciles con poder judicial, como Andrés Rodríguez, a quien por ser persona de confianza se le mandó a dirigir la residencia en las villas de Utrera, Alcalá de Guadaira, Lebrija, Las Cabezas de San Juan, Villamartín, Villafranca y Dos Hermanas ${ }^{8}$. Los otros oficiales enviados a las villas de la tierra eran escribanos reales, encargados de llevar a cabo los interrogatorios según una plantilla que les era entregada y de poner por escrito todas las actuaciones llevadas a cabo para la visita y pesquisa secreta9. En total se nombró a siete escribanos reales para viajar a las villas del territorio de Sevilla, que fueron:

- Gerónimo Andrés de Quevedo para ${ }^{10}$ :

- Aznalcóllar

- Castilleja del Campo

7. De este documento, originalmente signado por Tomé Sánchez, escribano del concejo, ha llegado hasta nosotros una copia posterior, aunque casi contemporánea, que se incluyó junto a los documentos de la pesquisa y residencia que fueron enviados a la Corte. AGI, CRC, 276.

8. AGS, CRC, 275: E porque yo en persona no puedo salir a tomar la residençia en las villas de la tierra donde se a de tomar por estar ocupado en tomar la residencia de la dicha çiudad, y es necesario que se pregone la dicha residençia con brebedad y se tome en todas las villas e lugares de la tierra la pesquisa e ynformaçión [...] combiene que para el dicho heffeto se ynbíe persona de espiriençia e confiança, y confiando de vos, Andrés Rodríguez, que soys tal persona que seguro aréys el seruiçio de Dios e de su Magestad, que con mucha delegencia y secreto haréis lo que por mí os sea cometido y mandado. [...] vos nombro por tal alguacil para que bays a las villas de Utrera, Alcalá de Guadayra, Lebrixa, Las Cabeças de San Juan, Villamartín, e Villafranca e Dos Hermanas [...]

9. AGS, CRC, 275: En la çiudad de Seuilla, a veinte días del mes de mayo de mil e quinientos e setenta años, el muy magnífico señor licenciado Morales, juez de residencia en esta dicha çiudad por su Magestad, en presençia de mí, Juan de Hermosilla, escriuano de su Magestad e de la dicha residencia, dixo que nonbraba e nonbró por escriuano a Antonio de Náxera, escriuano de su Magestad, para que como tal baya con bara de justizia al partido e lugares de la tierra desta çiudad que son Constantina, Caçalla, El Pedroso, San Niculás, Alanís, La Puebla de los Infantes, y en cada uno de los dichos lugares haga pregonar la residençia que al presente se toma por mandado de su Magestad al conde de Monteagudo e a sus tenientes e oficiales e otras justizias e personas de los dichos lugares. E apregonada, haga ynformaçión secreta por el tenor del ynterrogatorio que se le entregará e ynstruçión que para ello le mando dar recaudo, ynserto en la comissión que su merçed tiene para tomar la dicha residençia. Y se le dio comissión en forma y lo firmó de su nombre. El liçençiado Morales

10. AGS, CRC, 283. 
- Escacena del Campo

- Manzanilla

- Paterna del Campo

- Salteras

- Pedro Durán para ${ }^{11}$ :

- Alcalá de Guadaíra

- Dos Hermanas

- Las Cabezas de San Juan

- Lebrija

- Utrera

- Villamartín

- Villafranca de la Marisma

- Juan de Hermosilla para ${ }^{12}$.

- Alanís de la Sierra

- Bollullos

- Hinojos

- Sanlúcar la Mayor

- Antonio de Nájera para ${ }^{13}$.

- Cazalla de la Sierra

- Constantina

- El Pedroso

- La Puebla de los Infantes

- Fernando de Quesada para ${ }^{14}$ :

- Alcalá del Río

- Almadén

- Burguillos

- Cala

- Castilblanco

- Cumbres de San Bartolomé

- Cumbres Mayores

- Cumbres Menores

- El Garrobo

11. AGS, CRC, 279.

12. AGS, CRC, 283, 284.

13. AGS, CRC, 284.

14. AGS, CRC, 280.

Ediciones Universidad de Salamanca / 요 Stud. his., H. ${ }^{a}$ mod., 42, n. 1 (2020), pp. 223-253 
- Encinasola

- Gerena

- Guillena

- Hinojales

- La Nava

- La Rinconada

- Real de la Jara

- Santa Olalla del Cala

- Ángelo Ruiz Pérez para ${ }^{15}$ :

- Bodonal de la Sierra

- El Cerro

- Fregenal de la Sierra

- Aracena

- Aroche

- Castillo de las Guardas

- Cortegana

- Galaroza

- La Higuera de la Sierra

- Zufre

- Francisco de Santa Cruz para ${ }^{16}$.

- Aznalcázar

- Coria

- Huévar

- La Puebla de Coria

- Pilas

En todos estos lugares, los escribanos reales tenían instrucciones de pregonar la residencia, investigar los documentos y actuaciones realizados por los oficiales públicos de la villa, tanto miembros del concejo, como oficiales reales y escribanos públicos, y finalmente realizar un interrogatorio secreto a cierto número de vecinos para obtener sus opiniones sobre la labor que éstos habían realizado (Collantes de Terán, 1998: 168).

En esta investigación nos hemos centrado exclusivamente en la investigación realizada sobre la actividad de los escribanos públicos de las villas. Un oficio, que

15. AGS, CRC, 281.

16. AGS, CRC, 283.

Ediciones Universidad de Salamanca / @@ Stud. his., H. ${ }^{a}$ mod., 42, n. 1 (2020), pp. 223-253 
debido a su importancia y a las implicaciones jurídicas y económicas que su trabajo conllevaba, estuvo desde sus orígenes fuertemente legislado por sucesivas normativas que buscaban hacer de él una actividad homogénea en los distintos territorios castellanos y que poseyese todas las garantías de autenticidad y fidelidad posibles.

Ya desde época de Alfonso X las atribuciones, sistemas de trabajo y cobros de salarios de los escribanos públicos castellanos fueron especificados en las distintas obras legislativas de la época. En el Fuero Real, Espéculo y en las Partidas ya se reunían una serie de normas específicas y obligatorias para los escribanos del Reino. Como en tantos otros aspectos de la vida política, social y económica del Reino durante la Baja Edad Media, la inestabilidad política y el desgobierno de unos monarcas siempre necesitados de alianzas y apoyo económico, provocaron la relajación de la estricta normativa, cuya aplicación fue volviéndose cada vez más laxa a medida que los distintos reyes fueron considerando que los oficios y cargos públicos podían servir como moneda de cambio para obtener favores y apoyos (Bono, 1991: 289-290; Rabadé, 1991). Durante los reinados de Juan II y Enrique IV se multiplicaron los oficios de escribanía con el fin exclusivo de entregarlos como merced o a cambio de dinero a personas que en muchos casos los cederían a parientes o allegados, propiciando así su ocupación por parte de personas sin la preparación necesaria para su ejercicio y consecuentemente un alejamiento respecto a la normativa alfonsí.

Esta situación de descontrol motivó a los Reyes Católicos -en 1480- a buscar el modo de imponer su poder y restablecer el orden en este vital oficio. En las ya mencionadas Cortes de Toledo se legisla sobre distintos temas como los sistemas de acceso al oficio de escribano, aunque en este caso la normativa sobre nombramiento era aplicable sólo a las ciudades y villas en las que las escribanías eran de provisión regia, dejando al margen a aquellas de nombramiento señorial o concejil como sería el caso de Sevilla; también se legisla acerca del sistema de renuncias de escribanías y sobre la consumición de los oficios innecesariamente acrecentados. De esta reunión surgirá, además, un año más tarde, ya en 1481, un nuevo arancel de escribanos públicos en donde se establecería qué cantidades podrían estos oficiales cobrar por su trabajo (Pardo, 1998: 525).

Algunos años más tarde, en 1503, se promulga la pragmática de Alcalá de Henares, nacida a consecuencia de lo acordado en las Cortes celebradas ese mismo año en la dicha ciudad (Pardo, 2010; Riesco, 2004; Rojas, 2004). En esta normativa se contienen instrucciones mucho más específicas sobre del desempeño real y efectivo del oficio de escribano público, definiendo el orden que se debía seguir a la hora de elaborar el registro de escrituras públicas y de expedir documentos signados para las partes.

Carlos $\mathrm{V}$ también emitió normativa relativa a las actividades de los escribanos, aunque el verdadero cuerpo legislativo que regularía este oficio durante el siglo XVI

Ediciones Universidad de Salamanca / అ@@ Stud. his., H. ${ }^{a}$ mod., 42, n. 1 (2020), pp. 223-253 
Ma LUISA DOMÍNGUEZ-GUERRERO

EL CONTROL DE ESCRIBANOS PÚBLICOS EN LA CORONA CASTELLANA:

UN JUICIO DE RESIDENCIA EN LA TIERRA DE SEVILLA (1570)

lo estableció Felipe II en la Nueva Recopilación de las Leyes de Castilla en 1567. Como explica A. Rodríguez Adrados en su artículo «Felipe II, legislador», no se trata de un trabajo legislativo como tal, ya que reúne leyes de monarcas anteriores, pero tampoco es una simple compilación de normas, ya que en ella se llevó a cabo una labor de reorganización y reducción de leyes anteriores, eliminando las obsoletas y añadiendo algunas normas nuevas acordes con el contexto en el que se elaboró (Rodríguez, 1998).

Partiendo de esta legislación, los escribanos comisionados para la residencia recibieron la orden de investigar si la actividad de los escribanos públicos se ajustaba en todos los casos a la normativa vigente. Para facilitar su labor, antes de marchar se les entregó un documento conteniendo las instrucciones sobre cómo debía desarrollarse su misión. En él se establecía que al llegar a cada villa, lo primero que debía hacerse era pedir al escribano del concejo del lugar que diese una lista conteniendo los nombres de todos los oficiales municipales de los últimos tres años. A continuación habría de pregonarse la residencia que iba a llevarse a cabo e inmediatamente después tenían que cerrarse bajo llave las escribanías de los escribanos públicos del pueblo para evitar que subsanasen errores u ocultasen pruebas. Tras su cierre, ya podría el escribano comisionado para la residencia analizar los registros y escrituras de estos oficiales públicos para determinar qué grado de cumplimiento habían realizado de la legislación vigente. Por último, la investigación concluiría tomando declaración a una serie de testigos, para lo que se les entregó también una lista con las veintiséis preguntas que debían hacer para la pesquisa secreta. De éstas, hay cuatro preguntas referidas a los escribanos públicos, que son la XIX, preguntando si los escribanos habían usado bien sus oficios, habían cobrado los derechos justos y los habían anotado al pie de la escritura, o si habían cometido alguna falsedad en sus documentos o en su actuación ${ }^{17}$; la XX, que indagaba en la parcialidad de los escribanos, preguntando si habían aceptado sobornos o habían favorecido a una parte frente a otra ${ }^{18}$; la XXI, donde se pregunta si los escribanos habían realizado sus

17. XIX: Yten, sy saben que los escriuanos de los juzgados de la çiudad de Seuilla e villas de su tierra y escriuanos del cabildo, asy en lo criminal como en lo civil, han vsado bien e fielmente de sus offiçios, sin llevarse derechos demasyados de los contenydos; sy han hecho alguna falsedad en sus escrituras y en sus ofiçios; sy han llevado algunos derechos por buscar las escrituras e proçesos; sy han asentado al pie de las escrituras los derechos que han lleuado, espeçialmente los escriuanos que han asistido con los alcaldes de la hermandad; e sy los dichos escriuanos del cabildo han guardado el secreto dél; e si an lleuado intereses y dádivas por lo tocante al dicho offiçio. Digan lo que saben.

18. XX: Yten, sy sauen que los dichos escriuanos, ansy de la çiudad como de las villas, ayan llevado cohechos y dádiuas e cosas de comer de las partes que ante ellos traýan pleitos, sy an sido amigos e parçiales de algunas de las partes e por las favorecer an fecho daño a las otras; sy an sido diligentes en tomar los testigos y en dar despacho a los que ante ellos letigan. Digan particularmente lo que saben.

Ediciones Universidad de Salamanca / అ@@ Stud. his., H. ${ }^{a}$ mod., 42, n. 1 (2020), pp. 223-253 
labores escriturarias de forma correcta y conforme a derecho, no dejando huecos en blanco en sus documentos validados para ser completados más tarde ${ }^{19}$; y la XXII, que cuestionaba el comportamiento público de los escribanos, las relaciones con sus vecinos y los posibles delitos que hubiesen cometido para buscar la absolución de un encausado ${ }^{20}$.

Entre el veintiuno de mayo y el veinticuatro de julio de ese año de 1570 los escribanos comisionados llevaron a cabo su labor investigadora, viajando a todos los pueblos de la jurisdicción hispalense para realizar sus visitas. Éstas eran puestas por escrito y remitidas al juez de comisión, el licenciado Morales, que estaba en la ciudad de Sevilla y era el encargado de realizar los cargos y acusaciones en función de las observaciones de sus escribanos.

A tenor de los documentos de la visita, puede decirse que los comisionados cumplieron fielmente con su trabajo, viajando pueblo por pueblo, cerrando los oficios de escribanía y analizando todos los documentos contenidos en ellos en busca de faltas o delitos que fuesen contra la normativa vigente. Faltas que, en definitiva, eran las siguientes:

- No tener aprobación del Consejo Real

- Cobrar más derechos de los que el arancel permitía.

- No escribir los derechos percibidos

- No poner el conocimiento de las partes implicadas en el negocio.

- Tomar las escrituras en minutas en lugar de por extenso.

- Validar las escrituras antes de haberlas terminado o firmarlas en blanco.

- Tomar partido o favorecer a alguna de las partes.

- No poner todos los testigos necesarios.

- No incluir el salvamento de errores

- No tener los registros bien concertados y validados.

19. XXI: Yten, sy saben si los tales escribanos ayan tomado las escripturas que ante ellos han pasado en minuta e si las han otorgado en blanco haziendo firmar a las partes e a los testigos por ellos; sy en las causas creminales an tomado los testigos en minuta e después los an engrosado y dado a firmar a las partes y esto an fecho espeçialmente a los testigos que no saben firmar; sy an sentenciado los procesos sin sustançiar, dexando en blanco los autos y an lleuado derechos en los pleitos tocantes al concejoen los casos que les toca.

20. XXII: Yten, sy saben que los tales escriuanos ayan tenido questiones y ruidos con algunas personas y los hayan tratado mal de obras e de palabras e por ser escriuanos no ayan sido castigados, si an encubierto las ynformaçiones que an fecho contra los delinquentes e si las an dado a las justiçias por los cohechos que les an dado, por lo qual an quedado sin puniçión o castigo y teniendo en pie las dichas ynformaçiones cada día los cohechan. Digan particularmente lo que saben. 


\section{LOS RESULTADOS DE LA RESIDENCIA}

Una vez conocidos los cargos de los que se les acusaban, los escribanos tenían derecho a presentar descargos en su favor, justificando o desmintiendo las infracciones supuestamente cometidas. Los resultados de las visitas de las doscientas siete escribanías bajo la jurisdicción de Sevilla han sido plasmados en el gráfico que se ofrece a continuación, de cuyo análisis pueden extraerse numerosas conclusiones acerca de cómo trabajaban los escribanos públicos del territorio de Sevilla y hasta qué punto respetaban la normativa que regulaba el ejercicio de sus oficios.

TABLA 1. Incidencia de faltas en las escribanías visitadas.

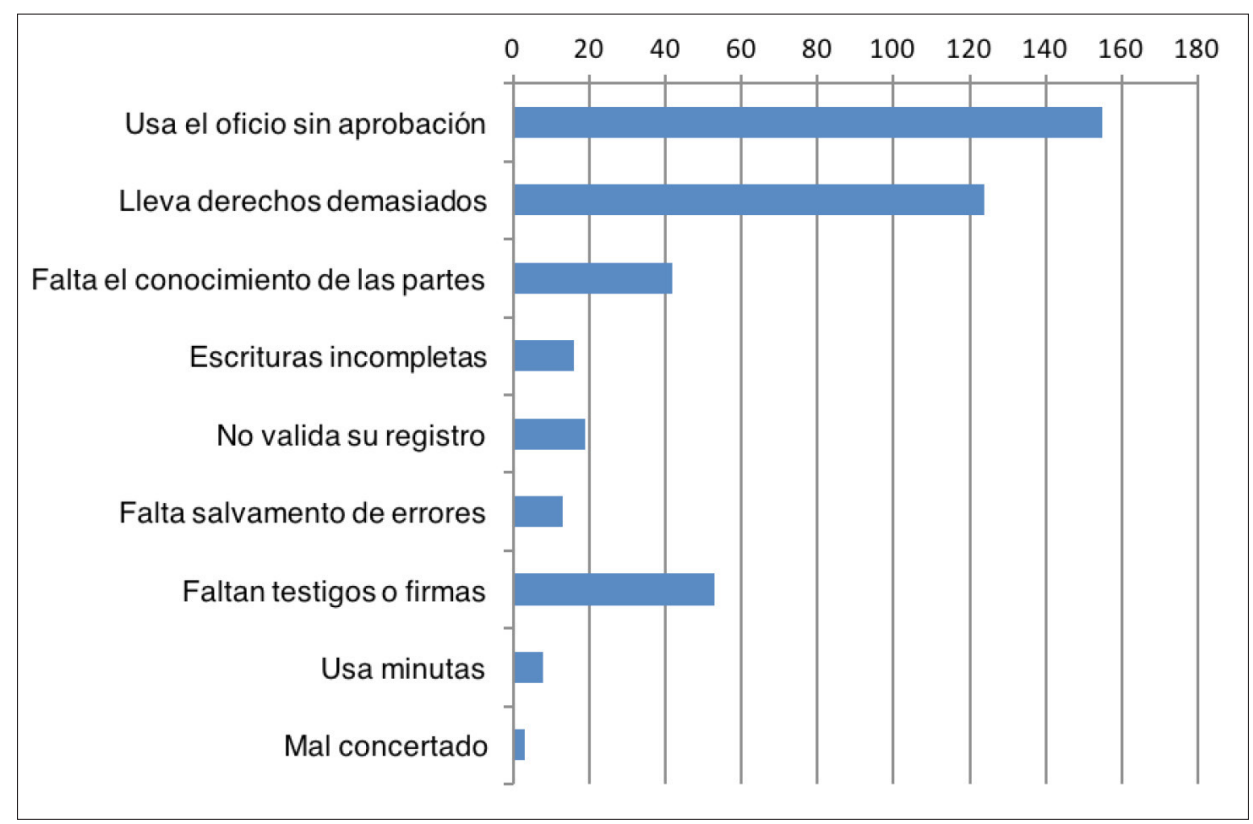

Fuente: Elaboración propia.

\subsection{La falta de aprobación real}

La aprobación real a la que este apartado se refiere forma parte de las modificaciones en el sistema de acceso al oficio de escribano público impuesta por Felipe II en su Nueva Recopilación de Leyes de Castilla, que establecía que los escribanos que hubiesen recibido su nombramiento a manos de un poder señorial o municipal

Ediciones Universidad de Salamanca / @@ Stud. his., H. ${ }^{a}$ mod., 42, n. 1 (2020), pp. 223-253 
sólo podrían seguir ejerciendo sus oficios tras haber sido aprobados por el Consejo Real, pues de lo contrario serían considerados falsarios ${ }^{21}$.

Esta norma contravenía los tradicionales privilegios de nombramiento de escribanos públicos de los que la ciudad de Sevilla había disfrutado desde el siglo XIV, obligando a los escribanos públicos a desplazarse hasta la Corte en busca de una aprobación. Como se observa en los resultados de la pesquisa, en 1570, apenas tres años después de la promulgación de esta ley, los escribanos públicos del término de Sevilla aún no se hallaban muy concienciados de la importancia y obligatoriedad de esta aprobación para seguir trabajando, y es que de los 207 notarios visitados, 155 habían ejercido su oficio sin contar con licencia regia, lo que constituye un $75 \%$ del total22.

\subsection{El cobro excesivo de derechos}

La acusación de esta falta podía venir originada por dos motivos principales. Uno de ellos era que en la fase de la pesquisa secreta a los testigos alguno acusase directamente a algún escribano de cobrar en exceso, cosa que sucedió varias veces. El otro motivo era que al revisar los documentos y libros de protocolos de los escribanos, el juez de residencia hallase que faltaban anotadas algunas cantidades.

En cuanto al primer motivo, cinco testigos de cinco pueblos diferentes acusan a alguno o a todos los escribanos de sus villas de cobrar en exceso. En algunos casos, como en Utrera, Santa Olalla y Palomares, las acusaciones son directas pero poco concretas, limitándose los testigos a decir que ellos les han visto llevar derechos demasiados. En el caso de Hinojales la acusación es más leve, puesto que el testigo sólo ha escuchado estos rumores pero no los ha presenciado él mismo.

El caso contrario es el de Escacena, donde hasta tres testigos informan con detalle sobre los excesivos derechos que Martín Hernández, escribano del concejo de la villa, estaba llevándose a costa de la institución municipal. Uno de ellos afirma:

lleva derechos demasiados al conçejo en cantidad cada año de nueue ducados de más del salario que el conçejo le da, que son otros seys ducados. Y los alcaldes se los dan porque hace los repartimientos del pecho y la alcabala y por tomar las qüentas de la carne, aunque no deberían pagarle de más porque en su sueldo ya va incluido todo lo tocante al concejo.

21. Recopilación de Leyes de los Reinos, Libro IV, Título XXV, Ley II.

22. Una explicación mucho más detallada de este proceso y de las reacciones de los escribanos públicos de las villas de Sevilla puede hallarse en Domínguez Guerrero (2014).

Ediciones Universidad de Salamanca / అ@@ Stud. his., H. ${ }^{a}$ mod., 42, n. 1 (2020), pp. 223-253 
Mientras que otro añade: «Martín Hernández, escriuano, llevava del conçejo nueue ducados, los seys por los repartimientos e tres por las qüentas de la carne, de más de otros seys ducados de salario que le da el conçejo».

Sin embargo, a excepción de éstas que se han mencionado, no fue muy frecuente que los testigos declarasen tener información referente al adecuado cobro de los derechos ya que, según muchos de ellos explican, en sus pueblos no había un arancel de escribanos colgado en un sitio público como mandaban las ordenanzas, con lo que no podían saber si se les estaba cobrando en exceso o no. Esto lo declaran testigos de los lugares de Cala, Encinasola, Hinojales, El Real y La Nava, todos ellos villas de pequeña entidad, con menos de tres escribanías ${ }^{23}$, en los que era posible que la normativa no hubiese llegado en su totalidad o, lo que es más probable, que los escribanos considerasen que podían eludir la ley puesto que sus usuarios no tenían muchos otros con quien comparar su labor.

El segundo motivo para ser acusado era la ausencia de la anotación de los derechos en el libro de protocolos. Entre los escribanos imputados por esta falta, hubo algunos que no pusieron absolutamente ningún derecho en ninguna escritura matriz, mientras que otros sólo los dejaron de poner en algunas escrituras concretas. De los primeros, hay varios que en su respuesta se limitan a negar los cargos, afirmando que eran falsos, mientras que otros justifican su ausencia remitiéndose a la antigua normativa.

El Arancel Nuevo de Escribanos, publicado en 1569, en su ley I, especifica que todos los documentos elaborados por escribanos públicos, así las escrituras signadas y sacadas como las matrices conservadas en el libro de protocolos, debían de llevar asentada la cantidad que habían costado ${ }^{24}$. Sin embargo, la normativa anterior, promulgada primero por los Reyes Católicos en las Cortes de Alcalá de 1498 y reafirmada después por Carlos V en una pragmática de 1521 y por Felipe II en su Nueva Recopilación de las Leyes de Castilla de 1567 (ley VI), no era tan clara respecto a dónde debían de ser escritos los derechos ${ }^{25}$. En esta ley se indica que los derechos debían de ser escritos en cualquier escritura pero se especifica que

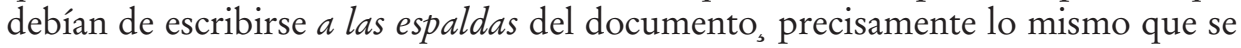

23. Cala, El Real y La Nava tenían dos, Hinojales tenía una y Encinasola tres.

24. Ansí en el registro como en los que dieren signado asienten los derechos que llevan de las partes y lo firmen de sus nombres y cuando no llevaren derechos lo asienten de la misma manera, so pena que de otra manera lo paguen con el quatro tanto para la Cámara.

25. Ley VI: Que todos los escribanos asienten los derechos en las espaldas de todo lo que ante ellos pasare y los de los jueces y en los mandamientos, antes de que los fagan firmar. Que asienten en las espaldas de los procesos y cartas de venta y poderes y obligaciones y otras cualesquier escrituras, los derechos que llevaren de las partes y los derechos que ellos y los alcaldes y otras personas llevaren, y lo firmen de su nombre para que si alguno se quexare que sepa lo que le llevaron

Ediciones Universidad de Salamanca / అ@@ Stud. his., H. ${ }^{a}$ mod., 42, n. 1 (2020), pp. 223-253 
establece en las ordenanzas de escribanos públicos dadas para otros lugares, como Córdoba, en 1493 (Ostos, 1995: 201) o Sevilla en 1492 (Bono y Ungueti, 1986: 32). El conflicto llega debido a que para poder escribir algo en el dorso de un documento éste tendría que tener libre la parte de atrás, cosa que sucede con los documentos signados entregados a las partes pero que no ocurre en los protocolos, donde a las espaldas de los documentos lo que se encuentra es una nueva escritura matriz.

Esta indefinición pudo provocar que los escribanos públicos asumiesen que los derechos debían de ser anotados en los documentos signados que daban a las partes, pero no en sus propios libros de registro de escrituras. Las cartas de descargo presentadas por varios de los escribanos públicos del alfoz parecen demostrar la existencia de esta confusión. Por ejemplo, Diego González de la Pava, escribano público y del concejo de Cazalla de la Sierra, explica que los derechos sólo faltan en los libros de protocolos anteriores a la promulgación del Nuevo Arancel, lo que indicaría que hasta ese momento no supo que debían de ser escritos en él.

A este desconocimiento de la obligatoriedad de escribir los derechos en los registros aluden también Alonso García, escribano público de Alanís de la Sierra, Esteban Sánchez, de Alcalá del Río, Rodrigo Simón, de El Bodonal, que indica que los derechos no se cobraban hasta que los documentos eran sacados, por lo que en la matriz no se podía anotar cuánto se cobraba; Francisco Pérez, de Burguillos, Juan de Campos, de Castilleja, quien además añade que, al fin y al cabo, el libro registro sólo lo vería él, así que a los otorgantes les daba igual que los escribiera o no; Bartolomé Miguel, de Castillo de las Guardas, Alberto Sánchez, de Cazalla de la Sierra, Alonso de Espinosa y Bartolomé Gómez, de Constantina, los cuatro del Pedroso, Agustín Pedroso, de La Puebla, Juan Hernández, de Paterna del Campo, y todos los escribanos de Utrera, quienes explican que: Según las leyes y arancel antiguo los escribanos sólo tienen que poner los derechos en los procesos.

Además de estos escribanos que nunca pusieron derechos en sus registros, había otros que los ponían sólo en algunas escrituras matrices, a los que también se acusó de cobrar en exceso. También ellos enviaron al juez de residencia sus cartas explicando la ausencia de estas anotaciones. La disculpa más frecuente es que se debió a un descuido, pero existen otras muchas razones. Antón Prieto, escribano público y del concejo en Bollullos de la Mitación, explica que él no anotaba los derechos en las escrituras que eran de muy poca calidad, sin indicar si se refería a la calidad de las partes implicadas, de la transacción llevada a cabo o de los derechos cobrados por su trabajo.

Nos decantamos por esta última opción ya que en este mismo sentido se manifiestan los tres escribanos públicos de Gerena, que afirman que sólo faltan derechos en aquellas escrituras por las que se recibe un pago tan escaso que queda anulada la ley que manda poner derechos. Sin embargo, no hemos hallado rastro en la normativa de esta anulación, ya que, hasta el momento ninguna normativa 
contradice la orden de anotar los derechos en todos los casos y no sólo cuando excediesen cierta cantidad.

También existían personas e instituciones a las que los escribanos públicos decían no cobrarles derechos. Los primeros son los pobres y vagabundos, a los que Gonzalo de Vallecillo, escribano púbico de Constantina, y Juan González, del Cerro, afirman no cobrar ninguna cantidad por sus escrituras. Tampoco pagaban, según explica Diego de León, escribano público de Fregenal, los parientes de los escribanos, las personas con las que tenían deudas y las iglesias, hospitales y monasterios, para los que se trabajaba gratis.

Esta exención de pago a las personas sin recursos parece ser una costumbre bastante generalizada, a pesar de no existir constancia de ella en los aranceles de escribanos publicados para reglar el cobro de sus derechos. Entre los registros analizados no son desconocidas las escrituras que se hicieron de forma gratuita cuando el otorgante no podía costeársela, aunque en estos casos lo correcto era anotar en el documento que no se habían llevado derechos por él, para así no caer en la falta de no anotar la cantidad al pie.

Aunque puede que esto no se hiciera antes de la visita, está claro que tras ella la normativa comenzó a aplicarse de forma mucho más estricta. Véase por ejemplo este documento escrito en 1570, apenas pocos meses después de la visita, realizado por Francisco Gómez Reinalte, escribano público de Fregenal de la Sierra, en que aclara, junto a la anotación de no haber llevado derechos, la razón por la que no los llevó: pobre.

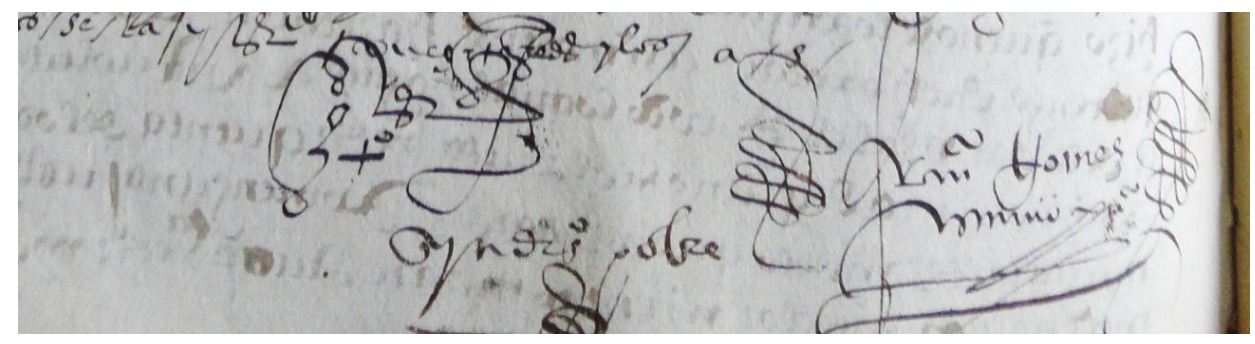

Figura 1. Archivo Histórico Provincial de Badajoz [en adelante AHPB], protocolos, 2763.

Finalmente, la última explicación ofrecida por algunos escribanos fue que los derechos no se anotaban hasta que se hubiese cobrado el dinero, y en muchos casos este dinero no llegaba a cobrarse porque los otorgantes se comprometían a pagar cuando fuesen a recoger los documentos sacados pero luego nunca lo hicieron.

Sin embargo, igual que en caso anterior, esta ausencia de pago no eximía al escribano de la obligación de anotar los derechos, con lo que lo legal habría sido

Ediciones Universidad de Salamanca / @®@@ Stud. his., H. ${ }^{a}$ mod., 42, n. 1 (2020), pp. 223-253 
anotar que no se había llegado a cobrar ninguna cantidad, como hizo este Francisco Gómez Reinalte, de Fregenal, a quien ya se ha puesto anteriormente como ejemplo de buen hacer: No reçibi derechos deste testamento porque no me los dieron.

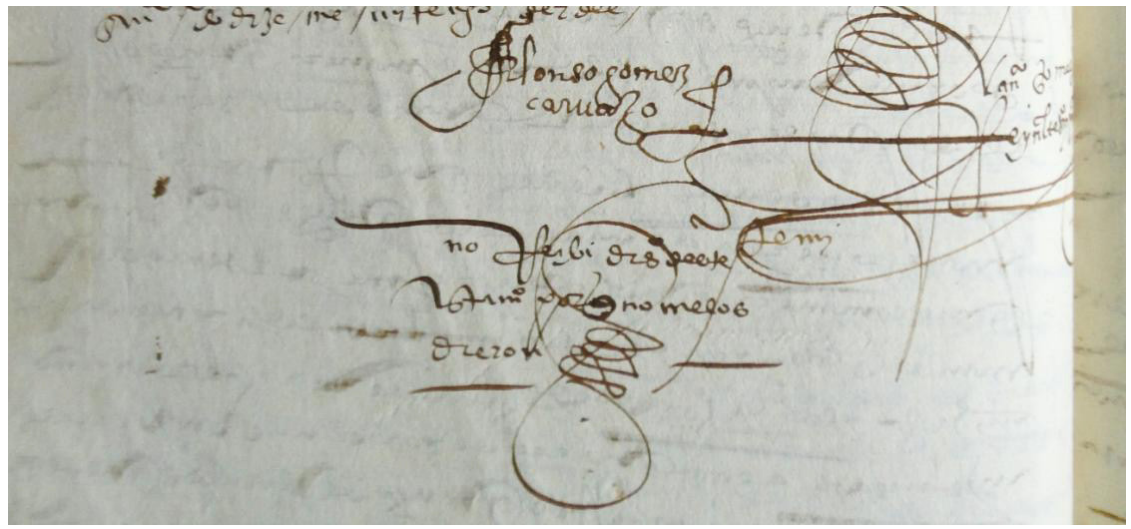

Figura 2. AHPB, protocolos, 2763.

\subsection{Ausencia de la cláusula de conocimiento de las partes}

El tercero de los cargos imputados a los escribanos públicos, que afectará al $20 \%$ de estos oficiales, será el de no haber incluido en el documento una cláusula en la que el escribano público diera fe de conocer personalmente a los otorgantes del mismo para evitar así fraudes y engaños. Una cláusula que la normativa indicaba claramente que debía de ser incluida en todos los documentos ${ }^{26}$. Pero pese a lo explícito de la ley y a su antigüedad (recuérdese que para el año en que se hizo esta visita de residencia esta ley llevaba vigente más de sesenta años) son muchos -cuarenta y dos- los escribanos a los que se acusa de su incumplimiento total o parcialmente.

En su defensa, un importante número de escribanos alegó que la obligatoriedad de explicitar que se conocía al otorgante tenía lógica en las ciudades, donde al haber tantos vecinos y una población tan oscilante era posible que los escribanos no conociesen a sus clientes y, por tanto, debían indicarlo expresamente cuando sí lo hacían.

26. Recopilación de las Leyes de Castilla, Ley XIV (Isabel I, Pragmática de Alcalá 1503): que cuando el escribano no conociere a las partes no haga ni reciba el contrato salvo si las partes presentan dos testigos, y en ese caso se nombre a los testigos al final de la escritura. Cuando sí conozca al otorgante, que dé fe en la suscripción de que lo conoce.

Ediciones Universidad de Salamanca / @®@@ Stud. his., H. ${ }^{a}$ mod., 42, n. 1 (2020), pp. 223-253 
En cambio, los escribanos afirman que en sus respectivas villas y pueblos, siendo de tamaño más reducido, todo el mundo se conocía y era ilógico tener que añadir una cláusula para un dato tan evidente. Esto es, por ejemplo, lo que presentaron en su descargo Diego García Girón, escribano público en Alcalá del Río, Lorenzo Pérez y Martín Alonso Casasanta escribanos públicos en Aracena, Rodrigo Simón, de El Bodonal, Antón Sánchez, escribano público de Cazalla de la Sierra, Juan González, de El Cerro, Pedro de Mercado, Alonso de Espinosa, Luis de Espinosa, Bartolomé Gómez y Francisco de Veas, escribanos públicos de Constantina, Francisco Díaz, de Cortegana, Gonzalo y Benito Díaz, de La Higuera, y Juan de Morales, escribano público de Sanlúcar la Mayor.

A esta alegación del reducido tamaño de los pueblos y villas, algunos escribanos añaden otro condicionante que les habría impulsado a tomar la decisión de no incluir esta cláusula, que no es otro que el condicionante económico. Son varios quienes afirman que en escrituras en las que los otorgantes son vecinos de la villa y el negocio es de poca entidad no existe necesidad de añadir cláusulas superfluas. Así lo afirmaron Francisco Pérez Cortegana, escribano público y del concejo de Burguillos, que pone como ejemplo los negocios sobre una o dos fanegas, Simón García, Juan de Acebedo y Pedro de Cáceres, escribanos de Gerena, Hernán Pérez, escribano en Guillena, que habla de negocios sobre dos o tres fanegas, Alonso Martín, también de Guillena, que baja el límite a una o dos fanegas y añade las cartas de poder como ejemplo de documento en el que no sería necesario poner el conocimiento de las partes, y Agustín Carrillo, de La Puebla.

Además del motivo económico, otros escribanos alegaron otras razones para excluir esta cláusula de conocimiento de algunos documentos concretos. Dos escribanos públicos y del concejo aludieron a su oficio como razón para no ponerlo: Fernando de Vallecillo, de Constantina, explica que la cláusula de conocimiento de las partes sólo falta cuando el negocio es entre oficiales del concejo ya que siendo él empleado en esta institución se da por supuesto que los conoce a todos bien. Juan Sánchez Hidalgo, en Alanís de la Sierra, va más allá y extiende este conocimiento evidente a todos los vecinos de su villa, ya que él era el encargado de elaborar los padrones municipales y por tanto tenía que conocer por fuerza a todos los vecinos y moradores.

El último en plantear una diferenciación entre qué documentos debían llevar el conocimiento de las partes y cuáles no fue Alonso de León, escribano público de Fregenal de la Sierra, quien explica que él sólo ponía el conocimiento en las cartas de obligación, ya que en el resto le parecía inútil, siendo como era un pueblo con un número reducido de habitantes.

Sin embargo la visita de residencia parece haber tenido resultados positivos sobre los escribanos, al menos en cuanto al cumplimiento de esta normativa se refiere, 
ya que en toda la documentación posterior a esta investigación se hallará ya esta cláusula en la práctica totalidad de los documentos.

\subsection{Ausencia de firmas y falta de testigos}

El siguiente cargo más importante en cuanto al número de infractores, abarcando al $25 \%$ de notarios, es el de no haber realizado las escrituras en presencia de los testigos que la legislación ordenaba y no haber validado las escrituras con el número de firmas pertinentes para cada caso, dos infracciones que, aunque diferentes, aparecen siempre combinadas en todas las cartas con los cargos debido a que normalmente se daban juntas.

La normativa establecía la obligatoriedad de que las escrituras matrices fueran firmadas por sus otorgantes en el momento del otorgamiento como sistema de validación y garantía de que la escritura era reconocida por ellos, indicándose que en el caso de que alguno de los otorgantes no supiera firmar debería hacerlo por él alguno de los testigos presentes al acto ${ }^{27}$. Además, era obligatorio que el otorgamiento de los negocios se llevase a cabo, no sólo ante el escribano público que le atribuía su fehaciencia, sino ante más personas que, en caso de pleito, pudiesen declarar que lo contenido en el documento se acordó como en él se decía.

El número de testigos que debían estar presentes al otorgamiento variaba en función de distintos factores. En la Partida III, Título XVIII, Ley LIV se especificaba que, salvo en los testamentos, los testigos debían ser dos escribanos de la villa $\mathrm{y}$, en caso de no hallarlos, que fuesen tres vecinos de ella. Esta normativa siguió vigente en la ciudad de Sevilla ya en época moderna, cuando las Ordenanzas para Escribanos Públicos de 1492 fueron promulgadas, reafirmando expresamente esta orden (Ostos, 1992: 192).

La única excepción a esta norma la plantea el caso de los testamentos que, siendo como son últimas voluntades, no podían ser pleiteados por sus otorgantes en caso de conflicto, por lo que requerían de una mayor seguridad. Por ello la legislación establecía que para los testamentos, tanto abiertos como cerrados, el número de testigos presentes al otorgamiento debía de ser mayor. Para testamentos abiertos o nuncupativos el número de testigos seguía siendo de tres, todos vecinos de la villa, siempre y cuando un escribano público estuviese dando fe de la veracidad del testamento. Si este oficial no se hallase presente, el número de testigos ascendía a

27. Pragmática de Alcalá 1503, ley XIII: Y que así como fueren escritas las tales notas los dichos escribanos las lean presentes las partes y los testigos y si las partes las otorgaren, las firmen de sus nombres y si no supieren firmar, firmen por ellos alguno de los testigos u otro que sepa escribir.

Ediciones Universidad de Salamanca / అ@@ Stud. his., H. ${ }^{a}$ mod., 42, n. 1 (2020), pp. 223-253 
cinco si eran vecinos de la villa o a siete si no lo eran. Para testamentos cerrados o inscriptis era obligatorio contar con un escribano público y siete testigos, ya que la carta cerrada debía de llevar ocho firmas ${ }^{28}$.

Cincuenta y dos de los doscientos siete escribanos del término de Sevilla fueron acusados de no poner más de dos testigos en sus escrituras matrices, contraviniendo así la ley. Para muchos de los escribanos esta acusación resultó una sorpresa, ya que afirmaron desconocer que habían estado cometiendo una falta al hacerlo así y creían estar trabajando conforme a la ley.

En la villa de Aracena, por ejemplo, son varios los escribanos públicos acusados por este cargo que dieron respuestas similares. Lorenzo Pérez, Diego Librero y Martín Alonso Casasancta, afirmaban en sus descargos que las leyes del reino permitían poner dos testigos, mientras que Alonso de Castilla realizaba una matización cronológica alegando que antes de la Nueva Recopilación bastaban dos testigos. Diego González de la Osa da un paso más allá al afirmar, erróneamente, que los dos testigos están recogidos en las Partidas salvo si es un testamento, ya que sólo en el caso de que los testigos fuesen escribanos públicos podrían ser dos.

La tradición también jugó un papel importante a la hora de justificar la ausencia de testigos. Martín Cid Rodero, escribano público de Aracena, Bartolomé Miguel y Pedro López, del Castillo de las Guardas, y Agustín de Cisneros, de Fregenal de la Sierra, alegaron todos que poner tres testigos no era costumbre en la villa. Y Juan Carmona, el mozo, escribano público en El Castillo de las Guardas, añadió que tradicionalmente se habian usado dos testigos y la ley lo aceptaba, sólo cuando fue aprobarse le avisaron del error.

28. Ley I (Alfonso XI, en Alcalá, 1386, Felipe II, en Madrid 1566) Que pone la solemnidad de testigos que son necessarios en el testamento nuncupativo: Si alguno ordenare su testamento o otra postrimera voluntad con escriuano público deuen ser presentes a lo ver otorgar tres testigos a lo menos, vecinos del lugar donde el testamento se hiziere, y si lo hiziere sin escriuano público que sean ahí a lo menos cinco testigos vecinos según dicho es, si fuere lugar donde los pudiere auer. Y si no pudieren ser auidos cinco testigos ni escriuano en el dicho lugar, a lo menos sean presentes tres testigos vezinos del tal lugar. Pero si el testamento fuere hecho ante siete testigos aunque no sean vezinos ni pase ante escribano, teniendo las otras calidades que el derecho requiere, valga el tal testamento. Ley II (Reyes Católicos, leyes de Toro 1505): que pone la solemnidad que se requiere en el testamento abierto y cerrado y en el del ciego y en el testamento entre hijos: Que lo anteriormente ordenado por Don Alfonso valga para los testamentos abiertos o nuncupativos, mientras que para testamentos cerrados o inscriptis, mandamos que intervengan a lo menos siete testigos con vn escriuano, los quales ayan de firmar encima de la escriptura del dicho testamentos ellos y el testador si supieren y pudieren firmar. Si no supieren y el testador no pudiere firmar, que los vnos firmen por los otros de manera que sean ocho firmas más el signo del escriuano.

Ediciones Universidad de Salamanca / అ@@ Stud. his., H. ${ }^{a}$ mod., 42, n. 1 (2020), pp. 223-253 
Otros escribanos públicos no negaron conocer la normativa pero alegaron la imposibilidad física de cumplirla. Algunos arguyeron que las villas en las que trabajaban eran tan pequeñas que resultaba imposible encontrar a tres personas que pudiesen estar presentes a los negocios notariales, como Mateo Díaz Galindo y Pedro González Polvillo, escribanos de Aznalcóllar, Juan González, de El Cerro, Martín Hernández, de Escacena, Juan Hernández Calvo, de Paterna del Campo, y Hernando Álvarez y Cristóbal Bernal, de Salteras.

Francisco Díaz, escribano en Cortegana, Alonso Pérez y Lorenzo Sánchez, de Zufre, entran en detalles y explican que los hombres de la villa se pasaban los días trabajando en los campos, con lo que no había ninguno disponible en la villa para acudir a las escribanías, siendo a veces necesario recorrer todo el pueblo para dar con tres vecinos. Esta escasez de hombres fue precisamente la que obligó al citado Alonso Pérez, escribano público de Zufre, a utilizar a mujeres como testigos de sus escrituras, un cargo por el que se le reprendió severamente.

La labor se complicaba mucho más cuando eran los escribanos los que tenían que desplazarse a casa del otorgante, especialmente cuando éstos vivían apartados del centro de la villa. Dos de los escribanos públicos de Aracena, Diego González de la Osa y Martín Librero, se defendieron diciendo: faltan firmas cuando las escrituras se hacen en los montes de la villa, donde no hay nadie que sepa escribir y apenas se encuentran testigos.

Esta carencia de testigos, y particularmente de testigos que supieran escribir, fue la que en muchos casos provocó, según explican los escribanos, que en los libros de protocolos faltasen firmas, ya que en muchas ocasiones los otorgantes no sabían firmar y no se podían encontrar en la villa vecinos letrados que supiesen firmar por ellos.

\subsection{Ausencia de signo en el registro}

Una de las obligaciones de los escribanos públicos, además de aportar fe pública a los actos que pasaban ante él, era conservar la memoria de esas actuaciones para garantizar que lo en ellas contenido se llevaba a cabo. Esta memoria la constituían precisamente las escrituras matrices que el escribano asentaba en su registro antes de entregarles el documento original a las partes que lo solicitaban.

Las escrituras de los protocolos eran -o al menos debían ser-validadas mediante las firmas de los otorgantes (o de testigos que firmasen en su nombre si ellos no sabían) y la suscripción del escribano público. Pero además de esto, para aportar una mayor seguridad y validez a los libros de registro, Carlos V ordenó, en las Cortes de Toledo de 1525 y lo reiteró en las de Segovia de 1532, que al final de cada año los

Ediciones Universidad de Salamanca / అ@@ Stud. his., H. ${ }^{a}$ mod., 42, n. 1 (2020), pp. 223-253 
registros fuesen validados mediante el signo del escribano público ${ }^{29}$ en la manera que se muestra a continuación en dos registros, el primero de Sanlúcar la Mayor de 1558 y el segundo, de Utrera de 1562.

Curiosamente, ninguno de los escribanos acusados de esta falta alegó nada en su defensa, aceptando implícitamente haber cometido esta infracción. Sin embargo, a ninguno de ellos se les aplicó la pena contenida en la ley para quienes incumplieran esta norma, que era de diez mil maravedís y la privación del oficio durante un año. No se han conservado todas las sentencias que el juez dio a todos los escribanos del territorio, pero a tenor del contenido de las que sí se conservan, está claro que ninguno de los escribanos recibió una multa de diez mil maravedís.

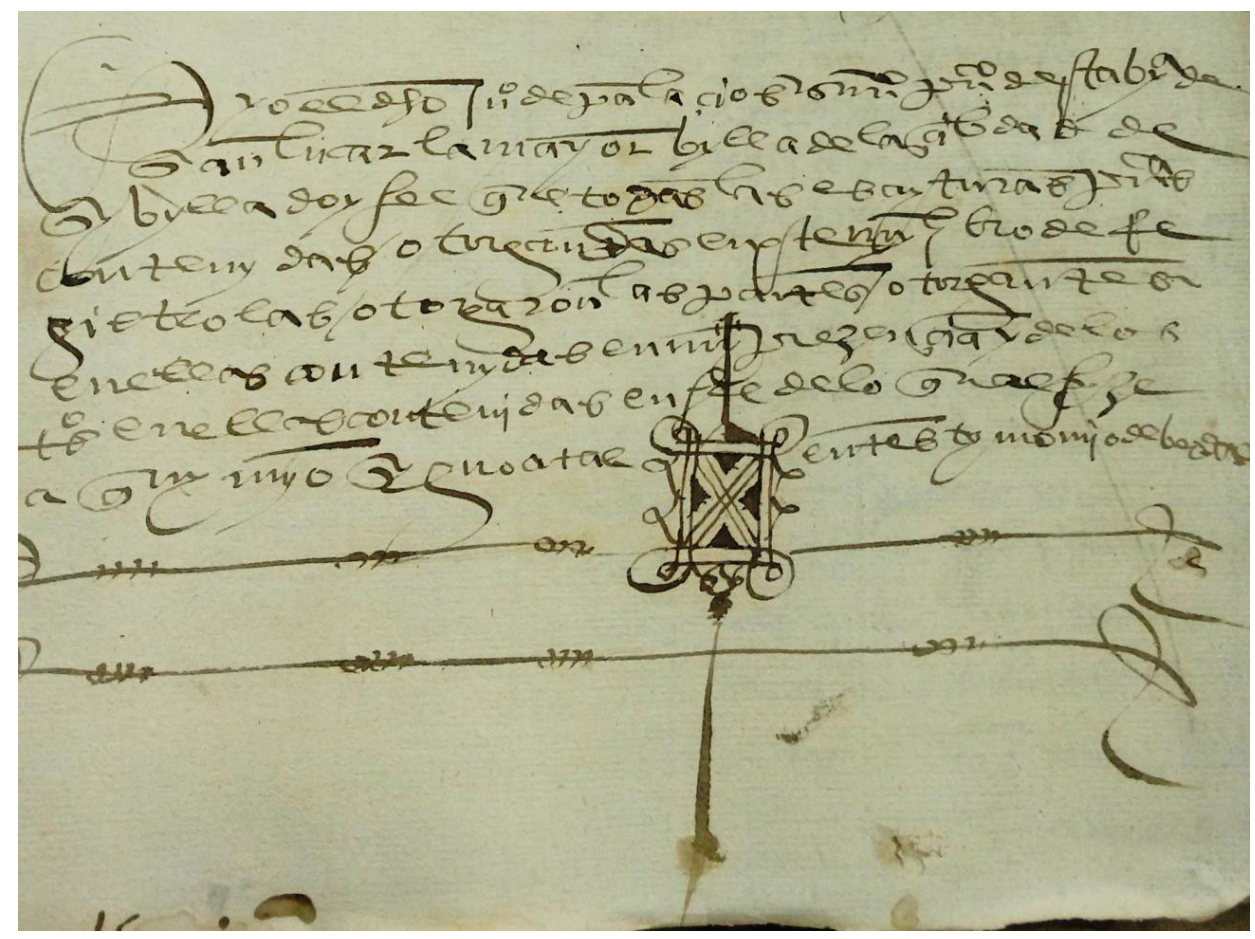

Figura 3. AHM Sanlúcar, protocolos, 1133.

29. Normativa que Felipe II recogió en su Nueva recopilación de leyes de castilla en Libro IV, Título XXV, Ley XII. 


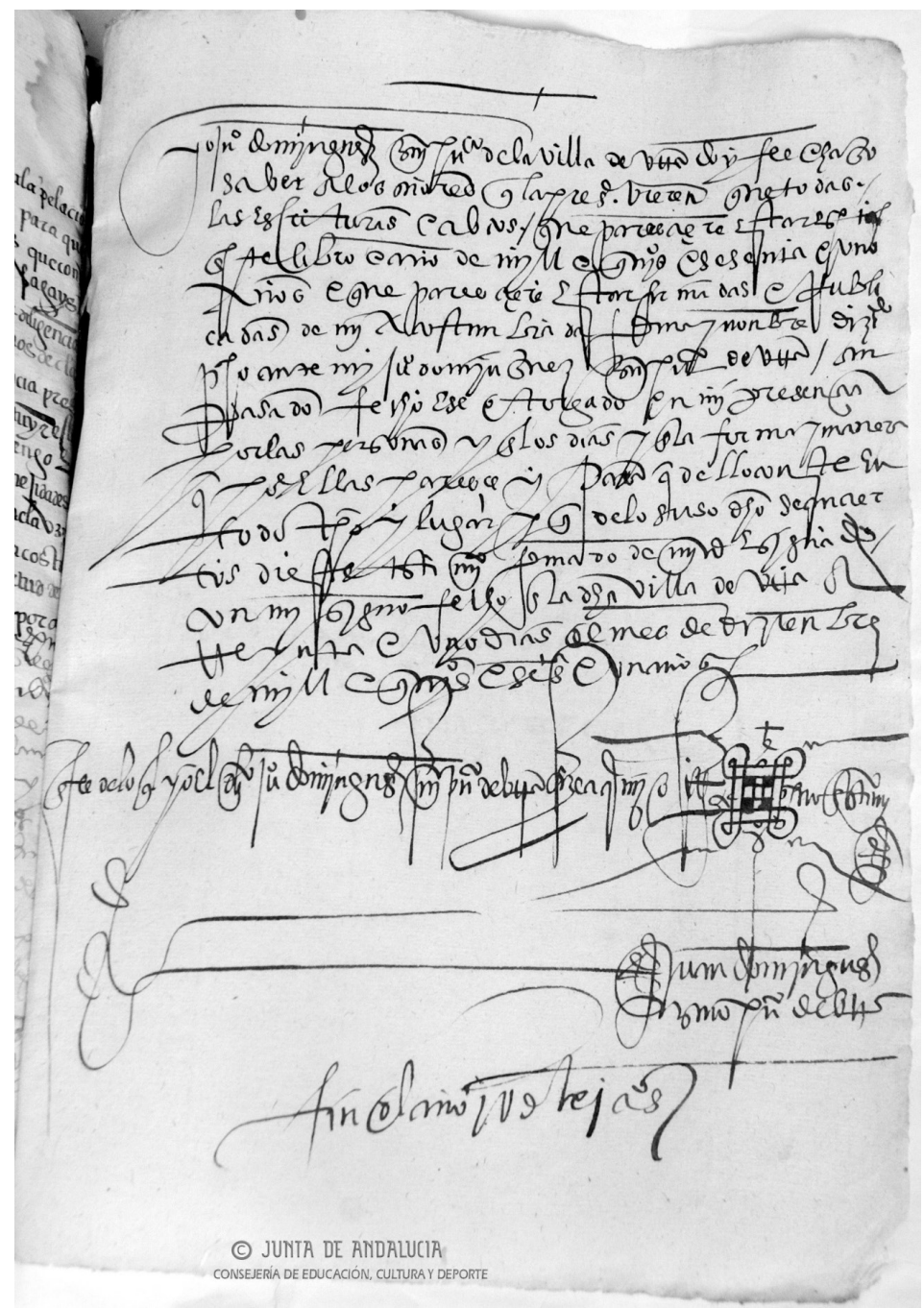

Figura 4. Archivo Histórico Provincial Sevilla (AHPS), protocolos, 22005.

\subsection{Realización de minutas por escrituras matrices}

Uno de los elementos en los que más hincapié hicieron los jueces que realizaban la residencia a los escribanos públicos fue en el hecho de si estos escribanos formalizaban correctamente sus instrumentos públicos o si, por el contrario, se

Ediciones Universidad de Salamanca / @@@ Stud. his., H. ${ }^{a}$ mod., 42, n. 1 (2020), pp. 223-253 
limitaban a anotar brevemente los datos del negocio, sin conferirles la forma y todos los elementos de validación que legalmente debían poseer, realizando lo que se denominaban escrituras en minuta, que el Diccionario de Autoridades de 1734 definía como «El extracto o borrador que se hace de algún contrato u otra cosa anotando las cláusulas o partes esenciales, para copiarse después y extenderse con todas las formalidades necesarias a su perfección ${ }^{30}$.

Estas escrituras podían tener cierto valor demostrativo de la realización de una actuación pero sólo dentro del propio oficio del escribano que las hizo, que nunca se preocupó en convertirlas en escritura matriz y por tanto no conservaba más recordatorio que ese, pero en ningún caso tuvieron un valor legal o probatorio como documento público porque de ninguna manera lo eran, ya que carecían de los más elementales sistemas de validación (no hay en ellas testigos, firma del otorgante o suscripción del escribano) y contravenían abiertamente la legislación vigente.

De hecho no fue un cargo muy frecuente ya que sólo a ocho de los escribanos visitados se les acusó de cometer esta falta, como Frutos Martínez y Martín Cid Romero en Aracena, o Lorenzo Rodríguez en Aroche. En la villa de Coria del Río fue el escribano del concejo, Juan de Parra, el que presuntamente conservó en minuta los autos relacionados con las rentas de la institución municipal, cargo que él negó en todo momento, afirmando que esas anotaciones eran para pasar a limpio.

\subsection{Otros delitos}

Finalmente, en los resultados de la visita aparecen también una serie de delitos diversos que, por su escasa frecuencia de aparición, no se han considerado pertinentes para constituir apartados individuales.

Algunos de ellos son defectos en la forma de elaborar sus instrumentos públicos, como Andrés del Águila, de Alcalá del Río, que se olvida de validar un proceso judicial, o Martín Librero, de Aracena, en cuyos codicilos no pone nunca la fecha del testamento al que se estaba refiriendo. También erran Mateo Díaz Galindo, de Aznalcóllar, que pone la data en lo que se denomina "cuenta castellana», es decir, en números romanos, en lugar de por extenso, y Juan Martínez de Vera, de Hinojos, que tenía en su registro algunas escrituras que no habían llegado a ser canceladas a pesar de que finalmente no se otorgaron. Frente a ello, tres de los escribanos públicos de la villa de Manzanilla, Lope Caro Becerra, Manuel Martínez y Juan de Osorno, fueron acusados de cancelar algunas escrituras sin dar ninguna explicación para ello.

30. O libros de escrituras menudas, como los designaban algunos escribanos públicos en la ciudad de Sevilla (Rojas, 2015).

Ediciones Universidad de Salamanca / అ@@ Stud. his., H. ${ }^{a}$ mod., 42, n. 1 (2020), pp. 223-253 
Otro grupo de defectos se relacionan más con la compilación, encuadernación y conservación de sus libros de protocolos. La falta más frecuente era la de tener los registros desordenados o descosidos, lo que supondría un grave problema a la hora de encontrar un negocio concreto si alguien lo solicitaba. Esto se complicaría aún más cuando los escribanos dejaban también de elaborar índices y abecedarios para sus libros registro. El caso más extremo es el de dos de los escribanos de Aroche, Hernán Mejía, el mozo, y Aparicio Hernández, que ni siquiera tenían libros registro, teniendo sus escrituras sueltas en bifolios y cuadernillos sin coser.

Finalmente, en el tercer grupo de faltas se encuentran aquellas relacionadas con el comportamiento que los escribanos mostraban no sólo en el desempeño de su profesión sino también en su vida personal, ya que de un oficial público se esperaba que fuese un hombre de buena vida y costumbres, aunque evidentemente, éste no fue el caso en muchas ocasiones.

A Alonso Hernández de Lariz, escribano público en Aznalcázar, varios testigos le acusan de llevar una vida inmoral y disoluta, hasta el punto de tener que ser prendido por la justicia de la villa, provocando escándalo e indignación en el pueblo:

Estando el dicho Alonso Hernández de Larín con una muger casada, fue el dicho Françisco Márquez, su marido, con la justiçia desta villa a los prender, que hera el dicho Alonso de Salas, alcalde que a la sazón hera, y en tratándolos prender el dicho Alonso Hernández se defendió de la justiçia y echó mano a la espada e se dio de cuchilladas con el dicho Francisco Márquez, su marido, e salió hiriendo. E por otra parte se salió la dicha muger, de lo qual vbo escándalo e alboroto e mal exemplo en la vecindad.

Este testigo, así mismo, a oýdo como cosa pública y çierta que el dicho Alonso Hernández de Laris, escriuano, fue herido por respeto que quería hablar o habló a vna doncella, hija de vezinos desta villa ${ }^{31}$.

Más graves aún fueron las acusaciones contra Martín Hernández, escribano público en Escacena del Campo, quien, además de la visita a su archivo y registros, se vio envuelto, por parte del juez de residencia, en una investigación específica centrada en su vida personal para averiguar si se había aprovechado de la situación de poder que su oficio le otorgaba para cometer todo tipo de abusos y deshonestidades. Y a tenor de las respuestas dadas por los testigos parece ser que sí que cometió numerosos delitos, acusándosele de abuso de poder, de decir obscenidades a las mujeres, de forzarlas y de tener relaciones con mujeres casadas ${ }^{32}$. Como muestra, se presenta esta declaración de una vecina de la villa:

31. AGI, CRC, 283

32. Casos similares se documentaron en las Alpujarras granadinas: de la Obra Sierra, J. M. Osorio Pérez, M. J., «Los escribanos de las Alpujarras (1500-1568)», El notariado andaluz:

Ediciones Universidad de Salamanca / 요 Stud. his., H. ${ }^{a}$ mod., 42, n. 1 (2020), pp. 223-253 


\section{Ma LUISA DOMÍNGUEZ-GUERRERO \\ EL CONTROL DE ESCRIBANOS PÚBLICOS EN LA CORONA CASTELLANA: UN JUICIO DE RESIDENCIA EN LA TIERRA DE SEVILLA (1570)}

Pareció Ysabel Molina e dixo que puede aver vn mes o mes y medio que estando el dicho Martín Hernández, escriuano, en casa le rogó que esta testigo le hablase a Leonor Díaz, muger de Juan Bázquez, para que se hechase carnalmente con él pues había hecho soltar a su marido de la cárzel ${ }^{33}$.

De esta misma villa de Escacena era Juan de Landa, a quienes sus vecinos acusaron de dar fe de hechos que eran falsos, de aceptar sobornos y de favorecer a unas partes sobre otras en función de dádivas o amistades personales. También le critican su costumbre de armar rencillas entre los vecinos y provocar enfrentamientos con el objetivo de que éstos terminasen en pleitos y él cobrase por escriturarlos.

Yten, que cohechó e llevó a muchos vezinos desta dicha villa el año pasado de sesenta y nueve y espiçialmente a Martín de Ortega, vezino desta villa.

Yten, que en un pleito que seguía Françisco Martín, vezino desta villa, contra vn pastor que le avía fecho vn daño en vn [...] suyo y se siguió antel dicho Juan de Landa que de Cumbreres presentó en nombre del dicho pastor en el dicho pleito dio por fee el dicho Landa cómo avían jurado en forma de derecho y no juraron. Yten, que el susodicho tiene costumbre de andar reboltando y alborotando en el pueblo y a dicho y publicado muchas vezes quel día que ay rebueltas y pleytos gana mejor en su ofiçio de escriuano

La defensa que elevó este escribano ante el juez de residencia se limitó a desprestigiar a los testigos que habían realizado estas declaraciones, afirmando que uno es un borracho y el otro un viejo loco que va por las calles con un cencerro.

En Higuera de la Sierra se encontraba Juan Martínez, escribano público y del concejo, a quien se acusó de no trabajar honestamente, siendo parcial y favorecer a unas partes, de llevarse dinero de las cuentas del concejo y de dar escándalos públicos.

Yten, se haze cargo al dicho scriuano que aviendo en su ofiçio de tener grand cuydado e deligencia de despachar los negoçios que ante él pasan con mucha brevedad dando despacho a las partes no lo a hecho, antes a sido remiso e negligente, parcial en el dicho despacho, favoresçiendo a vnas partes más que a otras, en especial lo hizo en el pleito que Juan Estevan Carmona trató con Rodrigo Alonso, cuñado del dicho escriuano, al qual no le quiso dar cierto testimonio por donde perdió su justiçia e, así mismo, no quiso dar otro testimonio a Christóbal Rodríguez en otro

institución, práctica notarial y archivos: siglo XVI, M. A. Moreno Trujillo, J. M. de la Obra Sierra, M. J. Osorio Pérez (coord.), Granada, 2011, pp. 89-126.

33. Baste esta declaración para mostrar hasta qué punto este escribano de pocos escrúpulos usó su posición de poder para aprovecharse de algunos vecinos de su villa. La investigación del juez de residencia, sin embargo, no concluye aquí ni mucho menos, siendo muchas más las historias escabrosas y los escándalos personales en los que este oficial público se vio envuelto. AGI, CRC, 283, p. 23v-31v

Ediciones Universidad de Salamanca / అ@@ Stud. his., H. ${ }^{a}$ mod., 42, n. 1 (2020), pp. 223-253 
pleito que trataba ante el dicho escriuano, en lo qual cometió delito e no hizo lo que hera obligado.

Yten se haze cargo al dicho Juan Martín, sriuano, que aviendo de tener grand qüenta e cuydado el día pasado de Corpus Christi de no alborotar la prosesión, ni que por su respeto se escandalizara ni hubiera alboroto en la dicha villa, y en la prosesión del Santísimo Sacramento no lo hizo, antes con poco temor de Dios, nuestro Señor, queriendo salir la prosesión y el Santísimo Sacramento por la fiesta que la iglesia celebraba, se asió a palabras e obras con Christóbal Rodríguez, que al presente llevaba la vara del Santísimo Sacramento, sobre si la avía de llevar o no. Fue tanto el alboroto que hizo, que el cura beneficiado de la yglesia de la dicha villa por lo evitar, vista la poca reberençia que el dicho Juan Martín tuvo al Santísimo Sacramento, fizo que el dicho palio se quedase en la iglesia.

\section{LAS PENAS DEL JUEZ DE RESIDENCIA}

Una vez realizada la información por el escribano real y tomadas las declaraciones de los testigos, esta documentación era enviada a Sevilla para ser estudiada por el juez de residencia, quien determinaría los cargos y las penas que habrían de imputarse a cada escribano público. Éstos les serían posteriormente notificados por los escribanos reales, dándoles cierto plazo, no determinado por la documentación, para realizar un documento de descargo en el que podían realizar las alegaciones que considerasen para justificar su inocencia y lograr su absolución.

La documentación conteniendo cargos y descargos volvería a ser puesta en manos del juez de residencia quien, vistas las alegaciones, determinaría la pena que debía de ser impuesta a cada escribano público, que sería nuevamente notificada a cada uno por los delegados del juez. Estas penas se hallaban establecidas en la propia normativa que regía la labor de estos oficiales, donde se determina que el castigo para el escribano que hubiese ejercido su oficio sin aprobación regia sería ser acusado de falsario y perder la mitad de sus bienes para la Cámara; los que cobraban derechos excesivos perderían el dinero ilegítimamente ganado, que sería para la Cámara Real; aquellos que no validasen sus libros de registro mediante su signo notarial pagarían diez mil maravedís para la Cámara; y todos los que firmasen o hiciesen firmar escrituras en blanco, los que no pusieran salvamento de errores, los que no asentasen correctamente las escrituras en el registro y los que sacasen copias de documentos sin autorización de juez en los casos en que ésta fuese necesaria serían condenados a perder su oficio para siempre.

De los doscientos siete escribanos visitados en el término de Sevilla, sólo se han conservado ciento diez sentencias, agrupadas al final de cada uno de los grandes libros en los que se cosían todos los documentos relacionados con el juicio de residencia. A través de su análisis podemos constatar que las penas recogidas en la

Ediciones Universidad de Salamanca / అ@@ Stud. his., H. ${ }^{a}$ mod., 42, n. 1 (2020), pp. 223-253 
legislación no fueron aplicadas en la mayoría de los casos, prefiriéndose siempre la sanción económica frente a la privación del oficio, a pesar de que éste último es el castigo más mencionado en la normativa.

Así, se ha visto que ciento cincuenta y cinco escribanos públicos se hallaban ejerciendo o habían ejercido en el pasado su oficio sin contar con la aprobación real, pero ninguno de ellos fue condenado a perder la mitad de sus bienes, un castigo que ni siquiera es mencionado en las sentencias. En cuanto a los escribanos que no signaban sus registros, ninguno de ellos recibió la sanción de diez mil maravedís, quizás porque al tratarse de escribanías rurales de escaso valor económico (Domínguez Guerrero, 2013), una sanción tan alta habría resultado imposible de afrontar, forzando al escribano a abandonar su oficio, mientras que una sanción más asequible garantizaría unos ingresos rápidos para la Cámara.

De esa manera, de los escribanos que habían cometido esta falta, Francisco de Tobar, escribano público de Castilleja, fue multado a pagar mil quinientos maravedís, Pedro López y Tomás López, del Castillo de las Guardas, pagaron tres mil maravedís cada uno; Alonso Esteban y Antón Sánchez, de Cazalla, fueron condenados a pagar cuatro ducados y dos mil maravedís respectivamente; Alonso Hernández, escribano público en La Puebla de Coria, debía de pagar tres mil maravedís, en Manzanilla, Lope Caro y Manuel Martínez pagaron dos mil y mil quinientos cada uno; Teodoro de Tebar y Cristóbal Bernal, de Sanlúcar la Mayor, recibieron seis ducados de multa y Pedro Hernández Cáceres, del mismo pueblo, dos mil maravedís. La pena más importante le llegó a Juan de Osorno, escribano público en Manzanilla, quien tuvo que pagar cinco mil maravedís. Una pena aparentemente algo desproporcionada teniendo en cuenta que apenas llevaba dos meses ejerciendo su oficio, con lo que no había tenido demasiado tiempo para cometer faltas de tanta importancia.

Todas las sentencias conservadas contienen penas económicas -ninguna de privación del oficio- que oscilan entre los dos ducados (setecientos cincuenta maravedís) y los siete mil quinientos mil maravedís. Con la pena más baja se hallan Hernando de Cantillana y Juan Romero, ambos escribanos públicos de Utrera, a quienes se acusó de no estar aprobados y de no anotar los derechos que llevaban, siendo la respuesta de los dos que ellos no necesitaban aprobación porque ya eran previamente escribanos reales además de públicos del número.

Frente a ellos, las penas más altas fueron recibidas por Martín Hernández, escribano público y del concejo de Escacena del Campo, acusado, como ya se mencionó, de mancillar mujeres y cobrar en exceso al concejo por sus servicios, que fue condenado a pagar cinco mil quinientos maravedís y a devolver al concejo todo lo que le había cobrado de más, y por Juan Martínez, escribano público y del concejo de Higuera de la Sierra, al que se condenó a pagar siete mil quinientos maravedís por organizar escándalos en el pueblo, manipular los repartimientos de

Ediciones Universidad de Salamanca / అ@@ Stud. his., H. ${ }^{a}$ mod., 42, n. 1 (2020), pp. 223-253 
alcabalas para beneficiar a sus amigos, robar dinero de los propios del concejo y negarse a expedir documentos si éstos perjudicaban a sus allegados.

Por su parte, el ya mencionado Juan de Osorno, escribano público de Manzanilla, fue condenado a pagar cinco mil maravedís porque en los dos meses que llevaba ejerciendo su oficio había cometido hasta seis faltas distintas, que eran no estar aprobado, no poner la cláusula de conocimiento de las partes, poner sólo dos testigos, no indicar los derechos que percibía cancelar documentos sin explicación y no validar los registros con su signo. Lo curioso del caso es que por la comisión de las mismas faltas, otros dos escribanos de la misma villa, Lope Caro Becerra y Manuel Martín, fueron condenados a pagar dos mil y mil quinientos maravedís respectivamente, lo que nos hace plantearnos si no habría otras causas ocultas para una pena tan elevada.

Entre ambos extremos, la mayor parte de los escribanos públicos fueron multados con cantidades que variaban entre los mil y los dos mil maravedís cuando habían cometido una o dos faltas, y tres mil maravedís para aquellos que habían cometido tres faltas o más.

\section{CONCLUSIONES}

Para finalizar hemos de recalcar que sólo diecisiete de los más de doscientos escribanos públicos visitados quedaron libres de cualquier culpa o acusación, lo que supone un número llamativamente reducido de profesionales que cumplían correcta y legalmente con sus obligaciones. Frente a ellos, los otros ciento noventa escribanos públicos que ejercían su labor bajo la jurisdicción de Sevilla fueron censurados por sus malas prácticas. Esto implicaría una observación bastante laxa de la normativa vigente, lo que por otra parte no es exclusivo de este territorio, ya que casi toda la literatura científica que toca el tema de las residencias y visitas, tanto en el territorio Peninsular como en los territorios ultramarinos, coincide en la frecuencia con la que estas auditorías destapaban malas prácticas en el seno del gobierno y las instituciones ${ }^{34}$.

En el caso de los escribanos del término de Sevilla, muchos de los acusados se limitaron a cometer faltas que, simplemente, delataban su falta de formación o su desidia a la hora de ejercer fielmente sus obligaciones, lo que se hallaría directamente relacionado con el sistema endogámico y restrictivo de acceso al oficio que se desarrollaba en la época. Los escribanos públicos castellanos no acudían a escuelas

34. Sería inútil aquí tratar de enumerar todos los trabajos que describen un juicio de residencia de un oficial público en el que éste fue acusado y condenado por sus malas prácticas, pero véanse aquí algunos como muestra: Jiménez (2015); Mendoza (2007); Cárdenas (2002) Osorio (2006) y López (1992).

Ediciones Universidad de Salamanca / అ@@ Stud. his., H. ${ }^{a}$ mod., 42, n. 1 (2020), pp. 223-253 
especializadas sino que recibían su formación práctica ejerciendo como aprendices y después ayudantes en el oficio de otro escribano experimentado (Rojas, 2016), empleando como apoyo teórico formularios específicos (Ostos y Domínguez Guerrero, 2014) que podían quedarse anticuados si no se renovaban con cierta asiduidad, algo que en las pequeñas notarías de las zonas rurales, en las que los escribanos apenas ganaban para subsistir, no parece probable. Por estas razones, es muy posible que muchas de las acusaciones de carácter técnico (como la omisión de la fórmula de conocimiento de las partes o del signo en el registro) que se realizaron a los escribanos públicos estén provocadas por un desconocimiento genuino de la normativa contemporánea. Al mismo tiempo, la situación socio-profesional de estos notarios rurales, muchas veces localizados en pueblos de muy escasa población, alejados de las grandes ciudades y del control de los oficiales reales, en los que muchas veces ellos eran uno de los escasos vecinos letrados, podía llegar a fomentar unas formas de trabajo más descuidadas y negligentes, precisamente debido a que su labor no sería puesta en tela de juicio por ninguno de sus usuarios.

Frente a ello, otros muchos escribanos contenidos en este estudio actuaron mal de forma consciente, aprovechando su posición privilegiada para beneficiarse a costa de sus clientes, ya fuera cobrándoles en exceso, tergiversando el contenido documental en favor de una de las partes, incitando a los vecinos a pleitear para así cobrar mayores tasas o incluso abusando de su situación de poder para cometer actos inmorales; todo lo cual no debió de hacer más que contribuir a la mala fama que tradicionalmente se achacó a este colectivo durante toda la Edad Moderna, que quedó claramente explicitada en la literatura de la época, tal y como distintos autores han recalcado (Extremera, 2005; Villaba, 2002), llegando a convertirse en una mención recurrente en el refranero popular y en muchas obras literarias (Marchant, 2004).

\section{BIBLIOGRAFÍA}

Bono Huerta, J.(1979). Historia del derecho notarial español, Madrid: Junta de Decanos de los Colegios Notariales de España.

Bono Huerta J. y Ungueti, C. (1986). Los protocolos sevillanos de la época del Descubrimiento, Sevilla: Junta de Decanos de los Colegios Notariales de España.

Cárdenas Gutiérrez, S. (2002). «Las insignias del rey: disciplina y ritual público en la ciudad de México", Jabrbuch Für Geschichte Lateinamerikas, 39, 193-216.

Collantes de Terán de la Hera, M. J. (1998). El juicio de residencia en Castilla a través de la doctrina jurídica de la Edad Moderna. Historia. Instituciones. Documentos, 25, 151-184.

Domínguez-Guerrero, M. L. (2014). El acceso al oficio de escribano público en el antiguo reino de Sevilla (siglo XVI). Funciones y prácticas de la escritura. I Congreso de investigadores noveles en Ciencias Documentales. Madrid: Lagomar Artes Gráficas, 57-69.

Domínguez-Guerrero, M. L. (2013). Distribución geográfica de las escribanías del reino de Sevilla en el siglo XVI. Documenta E Instrumenta, 11, 43-65.

Ediciones Universidad de Salamanca / అ@@ Stud. his., H. ${ }^{a}$ mod., 42, n. 1 (2020), pp. 223-253 
Ma LUISA DOMÍNGUEZ-GUERRERO

EL CONTROL DE ESCRIBANOS PÚBLICOS EN LA CORONA CASTELLANA:

UN JUICIO DE RESIDENCIA EN LA TIERRA DE SEVILLA (1570)

Domínguez Ortega, M. (1999). Análisis metodológico de dos juicios de residencia en Nueva Granada: D. José Solís y Folch de Cardona y D. Pedro Messía de la Cerda (1753-1773). Revista Complutense de Historia de América, 25, 139-165.

Extremera Extremera, M. A. (2005). El delito en el archivo. De escribanos, falseadores y otras gentes de mal vivir en la Castilla del Antiguo Régimen. Hispania: Revista española de Historia, 65, 465-484.

García Acuña, M. L. (1996). Mecanismos de control señorial: los juicios de residencia en el estado de Rivadavia. Obradoiro de Historia Moderna, 5, 119-134.

González Alonso, B. (1978). El juicio de residencia en Castilla, I: origen y evolución hasta 1480. Anuario de Historia del Derecho Español, 48, 249-271.

Jiménez Jiménez, I. (2015). Una herramienta inútil. Juicios de residencia y visitas en la audiencia de Lima a finales del siglo XVII. Temas Americanistas, 35, 60-87.

López Villalba, J. M. (1992). Concejo abierto, regimiento y corregimiento en Guadalajara (1346-1546). Espacio, Tiempo Y Forma, Serie III, $H^{\text {a } M e d i e v a l, ~ 5, ~ 65-83 . ~}$

Mendoza García, E. M. (2007). Juicio de residencia al escribano de Ardales en 1685: ¿Culpable o inocente?, Baetica, 29, 347-366.

Marchant Rivera, A. (2004). Aproximación a la figura del escribano público a través del refranero español. Condición social, aprendizaje del oficio y producción documental. Baética: Estudios de arte, geografía e historia, 26, 227-240

Obra Sierra, J. M., Osorio Pérez, M. J. (2011). Los escribanos de las Alpujarras (15001568). En M. A. Moreno Trujillo, J. M. de la Obra Sierra, M. J. Osorio Pérez (coord.), El notariado andaluz: institución, práctica notarial y archivos: siglo XVI. Granada: Universidad de Granada, 89-126.

Osorio Pérez, M. J., de la Obra Sierra, J. M. (2014). Los escribanos de la justicia. La justicia contra los escribanos. La visita del licenciado Huarte a las Alpujarras en 1560. En P. J. Arroyal Espigares y P. Ostos Salcedo (eds.), Los escribanos públicos y la actividad judicial. III Jornadas sobre notariado en Andalucía. Málaga: Ediciones Encasa, 99-144.

Osorio, A. (2006). La entrada del virrey y el ejercicio de poder en la Lima del siglo XVII. Historia Mexicana, 55, 3, 767-829.

Ostos Salcedo, P. (1992). Diplomática notarial en la época colombina: fases de redacción y forma documental. Actas del Convegno Internazionale di studi per le celebrazioni colombiane "Tra Siviglia e Genova: commercio, documento e notaio nell'etá colombiana». Génova: Giuffrè, 187-212.

Ostos Salcedo, P. (1995). Los escribanos públicos de Córdoba en el tránsito de la Edad Media a la Edad Moderna. En P. Ostos Salcedo, M. L. Pardo Rodríguez (eds.), El notariado andaluz en el tránsito de la Edad Media a la Edad Moderna: I Jornadas sobre el Notariado en Andalucía. Sevilla: Ilustre Colegio Notarial, 171-256.

Ostos Salcedo, P. (2012). El documento notarial castellano en la Edad Media. Littera Antiqua. Estudios En Honor de Alessandro Pratesi, 19, 517-534.

Ostos Salcedo, P., Domínguez-Guerrero, M. L. (2014). Los formularios notariales castellanos y la documentación judicial. En P. J. Arroyal Espigares y P. Ostos Salcedo (eds.), Los escribanos públicos y la actividad judicial. III Jornadas sobre notariado en Andalucía. Málaga: Ediciones Encasa, 29-80.

Ediciones Universidad de Salamanca / 요 Stud. his., H. ${ }^{a}$ mod., 42, n. 1 (2020), pp. 223-253 
Pardo Rodríguez, M. L. (1998). Aranceles de escribanos públicos de Sevilla. Historia. Instituciones. Documentos, 25, 525-536.

Pardo Rodríguez, M. L. (2010). Lo privado y lo público. Juan Álvarez de Alcalá, escribano público de Sevilla (1500-1518). En Emilio Torné, Enrique Villalba (eds.), El Nervio de la República. El Oficio de escribano en el Siglo de Oro. Madrid: Calambur, 15-54.

Rabadé Obradó, M. P. (1991). Las escribanías como conflicto entre poder regio y poder concejil en la Castilla del siglo XV: el caso de Cuenca. Anuario de Estudios Medievales, 21, 247-276.

Riesco Terrero, A. (2004). Real provisión de ordenanzas de Isabel I de Castilla (Alcalá, 7-VI-1503) con normas precisas para la elaboración del registro público notarial y la expedición de copias autenticadas. Documenta E Instrumenta, 1, 47-79.

Rodríguez Adrados, A. (1998). Felipe II, Legislador. Felipe II y el notariado de su tiempo, textos separados de la "Gaceta de los Notarios», 97, 12-16.

Rojas García, R. (2004). La memoria de lo privado en lo público: los escribanos públicos sevillanos. Historia. Instituciones. Documentos, 31, 573-584.

Rojas García R. (2015). La práctica de los escribanos públicos de Sevilla: los manuales (1504-1550). Sevilla: Diputación de Sevilla.

Rojas García, R. (2016). Aprendiendo el oficio. Los escribanos de Sevilla a comienzos de la modernidad. En Dicebamus hesterna die: estudios en homenaje a los profesores Arroyal Espigares y Martín Palma. Málaga: Ediciones Encasa, 445-479.

Serra Ruiz, R. (1968). Notas sobre el juicio de residencia en época de los Reyes Católicos, Anuario de estudios medievales, 5, 531-546.

Usunáriz Garayoa, J. M. (1998). Señores y municipios: el juicio de residencia señorial en Navarra y el control del poder local. Anuario de Historia del Derecho Español, 68, 491-522.

Villalba, E. (2002). Sospechosos en la verdad de lo que pasa ante ellos. Los escribanos de la Corte en el Siglo de Oro: sus impericias, errores y vicios. Litterae: Cuadernos de Cultura Escrita, 2, 121-150.

Zumalacárregui L. (1946). Visitas y residencias en el siglo XVI. Unos textos para su distinción. Revista de Indias, 7, 917-935.

Ediciones Universidad de Salamanca / @@ Stud. his., H. ${ }^{a}$ mod., 42, n. 1 (2020), pp. 223-253 